\title{
Efeito da adição de probiótico em dietas de leitões desmamados sobre as características do sistema digestório e de desempenho ${ }^{1}$
}

\author{
Effect of the probiotic addition in diets of weaned piglets on the characteristics of the \\ digesting system and of performance
}

\author{
ROBLES-HUAYNATE, Rizal Alcides²; THOMAZ, Maria Cristina ${ }^{3}$; SANTANA, \\ Áureo Evangelista ${ }^{4}$; MASSON, Guido Carlos Iselda Hermans ${ }^{2}$; AMORIM, Alessandro \\ Borges $^{2}$; SILVA, Susana Zaneti ${ }^{5}$; RUIZ, Urbano do Santos ${ }^{2}$; WATANABE, Pedro \\ Henrique $^{2}$; BUDIÑO, Fábio Enrique Lemos ${ }^{6 *}$
}

\footnotetext{
${ }^{1}$ Parte da tese de doutorado do primeiro autor.

${ }^{2}$ Universidade Estadual Paulista, Faculdade de Ciências Agrárias e Veterinárias, Programa de PósGraduação em Zootecnia, Jaboticabal, São Paulo, Brasil.

${ }^{3}$ Universidade Estadual Paulista, Faculdade de Ciências Agrárias e Veterinárias, Departamento de Zootecnia, Jaboticabal, São Paulo, Brasil.

${ }^{4}$ Universidade Estadual Paulista, Faculdade de Ciências Agrárias e Veterinárias, Clinica Veterinária, Jaboticabal, São Paulo, Brasil.

${ }^{5}$ Universidade Estadual Paulista, Faculdade de Ciências Agrárias e Veterinárias, Jaboticabal, São Paulo, Brasil.

${ }^{6}$ Instituto de Zootecnia, Agência Paulista de Tecnologia dos Agronegócios, Secretaria de Agricultura e Abastecimento, Nova Odessa, São Paulo, Brasil.

*Endereço para correspondência: fbudino@iz.sp.gov.br
}

\section{RESUMO}

Os objetivos foram avaliar os efeitos da adição de diferentes concentrações de probiótico $(0 ; 200 \mathrm{e}$ $300 \mathrm{mg} / \mathrm{kg}$ de ração) em rações de leitões recém desmamados e em diferentes idades de abate, sobre as características do sistema digestório e desempenho zootécnico. Foram utilizados 35 leitões desmamados, distribuídos em delineamento em blocos casualizados em esquema fatorial $3 \times 2+1$ (três concentrações de probiótico $\mathrm{x}$ duas idades de abate + grupo abatido ao desmame). Foram abatidos cinco leitões no dia da desmama e os demais ao $31^{\circ}$ e $41^{\circ}$ dia de idade. Foram amostrados segmentos do duodeno e jejuno para a contagem de vilosidades, pesados o pâncreas e fígado e calculado o rendimento de carcaça. Para incidência de diarréia e desempenho, foram utilizados 30 animais e as avaliações foram realizadas nos seguintes períodos: $\mathrm{P} 1-0$ a 10, P211 a 20 e Período Total- 0 a 20 dias pós desmame. Não houve efeito das concentrações do probiótico sobre as características do sistema digestório e a incidência de diarréia, no entanto o ganho de peso e a conversão alimentar foram afetados. Concluiuse que o ganho de peso e a conversão alimentar de leitões suplementados com 200mg de probiótico/kg de ração foi melhor do que o grupo suplementado com 300mg de probiótico/kg de ração. As diferentes concentrações de probiótico adicionadas na ração de leitões não alteraram as características do sistema digestório, mostrando-se alterações apenas em relação à idade do abate.

Palavras-chave: Bacillus spp., densidade de vilosidades, incidência de diarréia, suíno.

\section{SUMMARY}

The aims were to evaluate the effects of the addition of different probiotic concentrations $(0$; 200 and $300 \mathrm{mg} / \mathrm{kg}$ of ration) in rations of pigs recently weaned and in different ages of slaughter, on the characteristics of the digesting system and performance. 35 weaned pigs were used, distributed in blocks randomized design in $3 \times 2+1$ (three probiotic concentrations $\mathrm{x}$ two ages of slaughter + group slaughter to the weaning). Five pigs were slaughter in the weaning day and the others to the 31 and 41 days of age. Were sampled segments of the duodenum and jejunum for counting villous, weighs the pancreas and liver and 
calculated the yield carcass. For diarrhea incidence and performance, 30 animals were used and the evaluations were accomplished in the following periods: P1 - 0 to $10, \mathrm{P} 2-11$ to 20 and Total Period - 0 to 20 days after wean. There was not effect of the probiotic concentrations on the characteristics of the digesting system and the diarrhea incidence, however the weight gain and the feed:gain ratio were affected. The conclusion are: The gain weight and feed:gain ratio of piglets supplemented with $200 \mathrm{mg}$ of probiotic/ $\mathrm{kg}$ of ration was better than the group supplemented with $300 \mathrm{mg}$ of probiotic/ $\mathrm{kg}$ of ration. The different probiotic concentrations added in the piglets rations did not alter the characteristics of the digesting system, being showed alterations just in relation to the slaughter age.

Keywords: Bacillus spp., diarrhea incidence, swine, villous density.

\section{INTRODUÇÃO}

$\mathrm{Na}$ suinocultura industrial, a fase pósdesmame apresenta-se como um momento crítico para o leitão, acarretando ingestão insuficiente de alimentos, digestão incompleta, alterações na estrutura do epitélio intestinal, ocorrência de diarréias e diminuição da imunidade. Essas modificações podem ser causadas pelo desequilíbrio da microbiota intestinal (BHANDARI, 2008). Assim, VenteSpreeuwenberg et al. (2004) concluíram que essas alterações explicam a grande queda no desempenho zootécnico dos leitões nos primeiros dias após o desmame. Todavia, ausências de agentes patogênicos concomitantemente de produtos tóxicos na mucosa intestinal possibilitam a integridade e desenvolvimento normal do epitélio. Desta forma, a mucosa íntegra representa a possibilidade de digestão dos alimentos e a absorção dos nutrientes de forma normal (CORREA et al, 2010).

Os probióticos, por suas características, podem atuar no hospedeiro mediante a redução da concentração de amônia no organismo, diminuição de transtornos digestivos e estímulo ao sistema imunológico, síntese de bacteriocinas e peróxido de hidrogênio, produtos que inibem o crescimento de determinadas cepas de microrganismos patogênicos, produção de ácidos graxos de cadeia curta e estímulo à liberação de enzimas como a lactase (GUARNER \& MALAGELADA, 2003). Todavia, a manutenção de uma microbiota intestinal estável com o uso de probióticos, serve como barreira contra microrganismos potencialmente patogênicos e propicia a obtenção de bons resultados zootécnicos, por melhorar a digestão e a absorção de nutrientes (BUDIÑO et al, 2006).

O comportamento do animal em resposta ao uso de probióticos é influenciado pelo tipo de probiótico, concentrações utilizadas, idade e constituição genética, tipo de exploração, manejo, uso de antibióticos e o ambiente de criação (BARROS et al, 2008). As respostas mais expressivas da administração de probióticos são notadas nos animais estressados e em recém desmamados (SILVA et al, 2007).

Portanto, os objetivos do presente trabalho foram avaliar os efeitos da adição de diferentes concentrações de probiótico $(0 ; 200$ e $300 \mathrm{mg} / \mathrm{kg}$ de ração) em rações de leitões recém desmamados e em diferentes idades, sobre a densidade das vilosidades, peso absoluto de órgãos, rendimento de carcaça, incidência de diarréia e desempenho zootécnico.

\section{MATERIAL E MÉTODOS}

O experimento foi conduzido no Setor de Suinocultura do Departamento de Zootecnia da FCAV-UNESP, Campus de Jaboticabal. Os animais foram alojados em baias individuais de $2,55 \mathrm{~m}^{2}$ 
(1,50 x 1,70m), separadas por divisórias de grades de ferro e vedadas com placas de madeirite, para evitar o contato entre leitões de diferentes baias. Os bebedouros eram do tipo vasocomunicante e os comedouros do tipo semi-automático. Os animais receberam ração e água à vontade.

Durante o período experimental foram utilizados escamoteadores de madeira e lâmpadas incandescentes de $100 \mathrm{~W}$ em cada baia, possibilitando o aquecimento individual dos leitões. $\mathrm{O}$ probiótico testado foi o Bacsol-vt ${ }^{\circledR}$ constituído por bactérias e levedura: Bacillus subtilis, Bacillus natto, Bacillus megaterium, Lactobacillus acidophilus, Lactobacillus plantarum, Lactobacillus brevis, Lactobacillus casei, Streptococcus lactis, Streptococcus faecalis, Streptococcus termophilus e Saccharomyces cerevisiae.

Foram formuladas duas rações basais (Tabela 1) para atender as exigências nutricionais mínimas dos animais, seguindo as recomendações de Rostagno et al. (2005). As rações basais foram preparadas e logo divididas em três partes com pesos similares, em seguida uma das partes foi re-misturado com $200 \mathrm{mg}$ de probiótico/kg de ração e a outra parte com $300 \mathrm{mg}$ de probiótico/kg de ração, obtendo-se as seguintes rações experimentais: RBRação basal (controle); RB200 - Ração basal + 200mg de probiótico/kg de ração; RB300 - Ração basal + 300mg de probiótico/kg de ração.

Para o estudo das características do sistema digestório foram utilizados 35 leitões, mestiços, machos castrados, desmamados aos 21 dias de idade, com pesos de $5,51 \pm 0,36 \mathrm{~kg}$ e distribuídos em delineamento de blocos casualizados, que controlaram o peso inicial dos leitões, em esquema fatorial $3 \times 2+1$ (três concentrações de probiótico $\mathrm{x}$ duas idades de abate e um grupo abatido ao desmame), sendo a unidade experimental representada por um leitão.

No dia do desmame foram abatidos cinco leitões, sendo os demais abatidos aos 31 e 41 dias de idade $(0 ; 10$ e 20 dias pós desmame, respectivamente), após jejum alimentar de 12 horas, sem restrição de água.

O abate foi realizado mediante desensibilização por eletro choque e posterior sangramento. Após o abate, retiraram-se as vísceras, amostrando-se duas porções de três centímetros do duodeno e jejuno para a avaliação da densidade das vilosidades. Também, foram pesados o fígado, o pâncreas e a carcaça. O cálculo do rendimento de carcaça foi realizado segundo Bridi et al. (2006).

Posteriormente, as porções do duodeno e jejuno foram fixadas em glutaraldeído a $3 \%$, lavadas em solução tampão cacodilato de sódio $0,1 \mathrm{M}, \mathrm{pH} 7,2$ e fixadas em tetróxido de ósmio a $1 \%$. Na seqüência, as amostras foram desidratadas em série crescente de álcoois e logo mergulhadas em solução de acetato de isoamila por três horas. As amostras foram secas em secador de ponto crítico modelo SEM 850, utilizando $\mathrm{CO}_{2}$ líquido e metalizadas com $32 \mathrm{~nm}$ de ouro paládio, utilizando-se o aparelho DENTON VACUM modelo Desk II. Realizaram-se três elétronmicrografias por amostra em microscópio eletrônico de varredura JEOL, JSM 5410, operado a $15 \mathrm{kv}$. Os valores das densidades de vilosidades foram as médias aritméticas das quantidades de vilosidades de três fotografias que corresponderam a cada unidade experimental.

As pressuposições básicas e as análises estatísticas foram realizadas utilizandose o pacote computacional SAS (SAS Institute, 2003) e as médias foram comparadas pelo teste de Tukey (5\%). 
Rev. Bras. Saúde Prod. Anim., Salvador, v.14, n.1, p.248-258 jan./mar., 2013 http://www.rbspa.ufba.br ISSN 15199940

Tabela 1. Composições centesimal e nutricional das rações inicial, fornecidas aos leitões dos 21 aos 31 e dos 32 aos 41 dias de idade, respectivamente

\begin{tabular}{lrc}
\hline & \multicolumn{2}{c}{ Rações basais } \\
\cline { 2 - 3 } Ingredientes (\%) & Inicial 1 & Inicial 2 \\
\hline Milho & 60,07 & 57,82 \\
Farelo de soja (46\% PB) & 24,05 & 28,48 \\
Nuklospray * & 11,00 & 10,00 \\
Fosfato bicálcico & 2,36 & 1,74 \\
Calcário calcítico & 0,53 & 0,75 \\
Sal comum & 0,55 & 0,44 \\
Suplemento vit. min.** & 0,10 & 0,10 \\
L-Lisina. HCl (78,4\%) & 0,78 & 0,42 \\
DL-Metionina (99\%) & 0,16 & 0,08 \\
L-Treonina (98\%) & 0,31 & 0,14 \\
L-Triptofano (99\%) & 0,07 & 0,01 \\
Antioxidante & 0,02 & 0,02 \\
\hline Total & 100,00 & 100,00 \\
\hline Valores calculados & & \\
Matéria seca (\%) & 89,07 & 88,91 \\
Energia metabolizável (kcal/kg) & 3.377 & 3.361 \\
Proteína bruta (\%) & 20,00 & 21,00 \\
Cálcio (\%) & 0,89 & 0,83 \\
Fósforo total (\%) & 0,75 & 0,65 \\
Fósforo disponível (\%) & 0,56 & 0,45 \\
Lactose (\%) & 4,40 & 4,00 \\
Lisina digestível (\%) & 1,52 & 1,33 \\
Metionina digestível (\%) & 0,43 & 0,37 \\
Triptofano digestível (\%) & 0,26 & 0,23 \\
Treonina digestível (\%) & 0,96 & 0,84 \\
\hline Nuklospray k10-40\% lactose & & \\
\hline
\end{tabular}

*Nuklospray k10-40\% lactose.

**O suplemento mineral e vitamínico, não continha qualquer tipo de promotor de crescimento ou antibiótico. Concentrações de garantia por kg do produto: Ácido fólico-500mg; Selênio-150mg; Cobre$10000 \mathrm{mg}$; Pantotenato de cálcio-15000mg; Biotina-100mg; Manganês-23000mg; Iodo-400mg; Niacina-

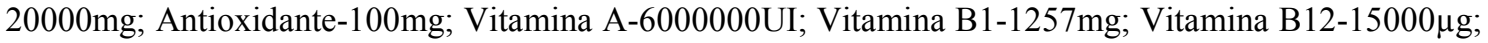
Vitamina B2-3336mg; Vitamina B6-1257mg; Vitamina D3-1500000UI; Vitamina E-13000mg; Vitamina K-2000mg e Zinco-80000mg.

O desempenho e a incidência de diarréia foram avaliados nos mesmos leitões citados anteriormente, à exceção dos cinco abatidos no dia do desmame, sendo, portanto, 30 leitões. As avaliações foram realizadas em períodos: $\mathrm{P} 1-0$ a $10, \mathrm{P} 2-$ 11 a 20 e Período Total- 0 a 20 dias pós desmame.

Durante os 20 dias do ensaio, foi realizada a avaliação dos escores fecais dos leitões. Uma vez ao dia, no período da manhã, verificou-se a característica física das fezes, mediante análise visual com os seguintes critérios: fezes de consistência dura (1), fezes pastosas (2) e fezes líquidas (3). Os escores 1 e 2 foram considerados fezes não diarréicas e o escore 3 foi considerado diarréia.

Foram avaliados o consumo diário de ração, o ganho diário de peso e a conversão alimentar a partir dos valores de peso corporal e consumo total de ração, determinados no dia do desmame e aos 10 e 20 dias pós desmame.

Utilizou-se o delineamento em blocos casualizados, para controlar as diferenças inicias no peso, com covariável (peso dos animais no início do segundo período), 
com três tratamentos e dez repetições por tratamento no P1 e cinco repetições por tratamento no $\mathrm{P} 2$, sendo que a unidade experimental foi representada por um leitão. As médias foram comparadas pelo teste de Tukey (5\%). Para a avaliação da incidência de diarréia foi utilizada a estatística não paramétrica, sendo as médias comparadas pelo teste de Kruskall-Wallis (5\%).

\section{RESULTADOS E DISCUSSÃO}

Os resultados obtidos mostram que as diferentes concentrações de probiótico utilizadas nas rações não afetaram $(\mathrm{P}>0,05)$ a densidade das vilosidades. Entretanto, esta variável foi influenciada $(\mathrm{P}<0,05)$ pela idade dos leitões (Tabela 2).

Tabela 2. Densidade de vilosidades (vilosidades $/ \mathrm{cm}^{2}$ ) do duodeno e jejuno em função da concentração de probiótico $(\mathrm{mg} / \mathrm{kg})$ e idade dos leitões

\begin{tabular}{lcc}
\hline \multirow{2}{*}{ Fatores } & \multicolumn{2}{c}{ Segmentos do intestino delgado } \\
\cline { 2 - 3 } & Duodeno & Jejuno \\
\hline Concentração do probiótico & $\mathrm{P}=0,63$ & $\mathrm{P}=0,75$ \\
Idade pós desmame & $\mathrm{P}=0,0004$ & $\mathrm{P}=0,0001$ \\
Interação & $\mathrm{P}=0,69$ & $\mathrm{P}=0,62$ \\
\hline CV $(\%)$ & 22,78 & 16,34 \\
\hline Concentração do probiótico & - & - \\
0 & $8319 \pm 641$ & $8851 \pm 644$ \\
200 & $8066 \pm 642$ & $9002 \pm 753$ \\
300 & $7687 \pm 504$ & $8528 \pm 447$ \\
\hline Idade pós desmame & - & - \\
0 & $10756 \pm 980^{\mathrm{a}}$ & $13208 \pm 700^{\mathrm{a}}$ \\
10 & $9226 \pm 498^{\mathrm{a}}$ & $10118 \pm 443^{\mathrm{b}}$ \\
20 & $6542 \pm 274^{\mathrm{b}}$ & $7249 \pm 339^{\mathrm{c}}$ \\
\hline a,b,c Médias seguidas de letras iguais na mesma coluna não diferem entre si pelo teste de Tukey $(\mathrm{P}>0,05)$.
\end{tabular}

No duodeno, observou-se similar $(\mathrm{P}>0,05)$ densidade de vilosidades nos dias 0 e 10 pós desmame, no entanto, nessas idades as densidades foram significativamente maiores $(\mathrm{P}<0,05) \mathrm{em}$ relação ao dia 20 pós desmame. No jejuno houve progressiva diminuição $(\mathrm{P}<0,05)$ da densidade de vilosidades conforme aumentou a idade dos leitões. Tucci et al. (2011) também observou diminuição progressiva da densidade de vilosidades no duodeno e jejuno de leitões desmamados e abatidos aos $0 ; 7$ e 14 dias pós desmame. Os autores argumentaram que a diminuição na densidade de vilosidades ocorre em razão do aumento em sua largura. Essa relação foi confirmada no estudo de Scandolera et al. (2005), que observaram maior densidade de vilosidades (7841vilosidades $\left./ \mathrm{cm}^{2}\right)$ e pequena largura de vilosidades $(115 \mathrm{~mm})$ no jejuno de leitões abatidos aos sete dias pós desmame.

Os resultados obtidos neste trabalho foram discordantes com as observações de Budiño et al. (2005), Scandolera et al. (2005) e Thomaz et al. (2011), em 
que observaram aumento e redução na densidade de vilosidades aos 7 e 14 dias pós desmame, respectivamente, comparado ao dia do desmame.

As diferentes concentrações do probiótico adicionadas nas rações de leitões recém desmamados não afetaram
$(\mathrm{P}>0,05)$ os pesos absolutos e relativos do fígado e pâncreas e a percentagem do rendimento de carcaça (Tabela 3 ). Entretanto, as idades dos animais influenciaram $(\mathrm{P}<0,05)$ todas as variáveis estudadas.

Tabela 3. Pesos absolutos e relativos ( $\mathrm{g} / \mathrm{kg}$ de carcaça) do fígado e pâncreas e rendimento de carcaça $(\mathrm{RC})$ de leitões em função de diferentes concentrações do probiótico $(\mathrm{mg} / \mathrm{kg})$ e idade

\begin{tabular}{lccccc}
\hline & \multicolumn{2}{c}{ Fígado } & \multicolumn{2}{c}{ Pâncreas } & RC \\
\cline { 2 - 5 } Fatores & $\begin{array}{c}\text { Peso absoluto } \\
(\mathrm{g})\end{array}$ & $\begin{array}{c}\text { Peso } \\
\text { relativo } \\
(\mathrm{g} / \mathrm{kg})\end{array}$ & $\begin{array}{c}\text { Peso } \\
\text { absoluto } \\
(\mathrm{g})\end{array}$ & $\begin{array}{c}\text { Peso } \\
\text { relativo } \\
(\mathrm{g} / \mathrm{kg})\end{array}$ & $\begin{array}{c}\text { R } \\
(\%)\end{array}$ \\
\hline Cc. do Probiótico* & $\mathrm{P}=0,73$ & $\mathrm{P}=0,52$ & $\mathrm{P}=0,72$ & $\mathrm{P}=0,83$ & $\mathrm{P}=0,65$ \\
Idade pós desmame & $\mathrm{P}=0,0001$ & $\mathrm{P}=0,0001$ & $\mathrm{P}=0,0001$ & $\mathrm{P}=0,013$ & $\mathrm{P}=0,0032$ \\
Interação & $\mathrm{P}=0,63$ & $\mathrm{P}=0,90$ & $\mathrm{P}=068$ & $\mathrm{P}=0,70$ & $\mathrm{P}=0,75$ \\
\hline CV $(\%)$ & 14,73 & 11,39 & 17,94 & 17,22 & 3,58 \\
\hline Cc. do Probiótico & - & - & - & - & - \\
0 & $111,0 \pm 4$ & $29,1 \pm 0,1$ & $7,4 \pm 0,2$ & $1,9 \pm 0,1$ & $76,6 \pm 0,5$ \\
200 & $142,8 \pm 5$ & $33,9 \pm 0,9$ & $14,6 \pm 0,6$ & $3,5 \pm 0,1$ & $68,5 \pm 0,4$ \\
300 & $255,3 \pm 7$ & $44,6 \pm 0,9$ & $24,0 \pm 1,1$ & $4,2 \pm 0,2$ & $64,3 \pm 0,6$ \\
\hline Idade pós desmame & - & - & - & - & - \\
0 & $198,9 \pm 16^{\mathrm{c}}$ & $40,4 \pm 2,1^{\mathrm{c}}$ & $19,2 \pm 1,9^{\mathrm{c}}$ & $3,9 \pm 0,3^{\mathrm{c}}$ & $65,8 \pm 1.1^{\mathrm{a}}$ \\
10 & $204,4 \pm 23^{\mathrm{b}}$ & $39,4 \pm 2,0^{\mathrm{b}}$ & $20,0 \pm 1,0^{\mathrm{b}}$ & $3,9 \pm 0,2^{\mathrm{b}}$ & $66,6 \pm 0,8^{\mathrm{b}}$ \\
20 & $193,9 \pm 22^{\mathrm{a}}$ & $38,1 \pm 2,1^{\mathrm{a}}$ & $18,7 \pm 1,8^{\mathrm{a}}$ & $3,7 \pm 0,2^{\mathrm{a}}$ & $66,8 \pm 0,8^{\mathrm{c}}$ \\
\hline
\end{tabular}

$\bar{a}^{a, b, c}$ Médias com letras iguais na mesma coluna não diferem entre si pelo teste de Tukey $(\mathrm{P}>0,05)$.

*Cc. do probiótico $=$ Concentração do probiótico.

Os pesos absolutos e relativos do fígado e pâncreas aumentaram progressivamente $(\mathrm{P}<0,05)$ com o aumento da idade dos leitões, indicando maior desenvolvimento e maturação da capacidade digestiva dos animais com as novas dietas fornecidas após o desmame. Em estudos semelhantes, Vente-Spreeuwenberg et al. (2004) também verificaram aumento do peso absoluto do pâncreas entre três e sete dias após o desmame. Da mesma forma, Scandolera et al. (2005), estudando cinco dietas e três idades de abate dos leitões observaram progressivo aumento dos pesos com a maior idade dos animais.

$\mathrm{O}$ rendimento de carcaça apresentou diminuição $(\mathrm{P}<0,05)$ progressiva com o aumento da idade dos animais, possivelmente, devido ao pequeno aumento de peso corporal observado nessa idade e ao maior desenvolvimento do sistema digestório.

As diferentes concentrações do probiótico utilizadas nas rações dos leitões não influenciaram $(\mathrm{P}>0,05)$ a incidência de diarréia (Tabela 4), concordando com o estudo de Utiyama et al. (2006), em que observaram que a suplementação de Bacillus subtilis $e$ Bacillus licheniformis nas rações de leitões desmamados não controlaram a diarréia quando comparado com leitões alimentados sem suplementação de probiótico. 
Em estudo anterior, com o mesmo probiótico e mesmas concentrações e com diferente constituição genética de leitões recém desmamados, indicou que a suplementação do produto nas rações dos leitões controlou $(\mathrm{P}<0,05)$ a incidência de diarréia (HUAYNATE et al., 2006). Portanto, a diferença do resultado pode ser devido à constituição genética dos animais e ao ambiente em que foram alojados, considerando que os desafios sanitários do ambiente de criação foram diferentes nesses dois estudos.

Tabela 4. Escores fecais e percentagem de diarréia de leitões alimentados com dietas contendo diferentes concentrações de probiótico $(\mathrm{mg} / \mathrm{kg})$, avaliados nos Períodos 1,2 e Total por tratamento

\begin{tabular}{|c|c|c|c|c|}
\hline Fezes/concentração do probiótico & 0 & 200 & 300 & $\%$ Total \\
\hline \multicolumn{5}{|c|}{$\mathrm{P} 1-0$ a 10 dias pós desmame $(\mathrm{P}=0,96)^{*}$} \\
\hline Fezes não diarréicas & 59 & 63 & 62 & 76,67 \\
\hline Fezes diarréicas & 21 & 17 & 18 & 23,33 \\
\hline$\%$ de Diarréia & 26,25 & 21,25 & 22,50 & - \\
\hline \multicolumn{5}{|c|}{ P2- 11 a 20 dias pós desmame $(\mathrm{P}=0,26)^{*}$} \\
\hline Fezes não diarréicas & 22 & 25 & 26 & 49,32 \\
\hline Fezes diarréicas & 28 & 23 & 24 & 50,68 \\
\hline$\%$ de Diarréia & 56,00 & 47,92 & 48,00 & - \\
\hline \multicolumn{5}{|c|}{$\mathrm{P}$ Total- 0 a 20 dias pós desmame $(\mathrm{P}=0,72)^{*}$} \\
\hline Fezes não diarréicas & 81 & 84 & 88 & 66,58 \\
\hline Fezes diarréicas & 49 & 36 & 42 & 33,42 \\
\hline$\%$ de Diarréia & 37,69 & 30,00 & 32,31 & - \\
\hline
\end{tabular}

*Teste de Kruskal-Wallis.

Da mesma forma, Shu et al. (2001) observaram menor incidência de diarréia, menor número de $E$. coli e Rotavírus e maiores títulos de imunoglobulinas, nas fezes de leitões suplementados com Bifidobacterium lactis em relação ao grupo controle sem suplementação, no período de cinco dias antes e nove dias depois do desmame. Os autores concluíram também que o controle da incidência de diarréia possivelmente seja devido ao mecanismo do aumento da proteção imunológica acarretada pelo microrganismo do probiótico. Também, Alexopoulos et al. (2004) observaram menor incidência de diarréia em leitões nas fases de aleitamento e pós desmame suplementados com Bacillus licheniformis e Bacillus subtilis, comparados àqueles do grupo controle sem suplementação de probiótico.
Os leitões sem suplementação do probiótico apresentaram aproximadamente $8 \%$ a mais de diarréia no Período Total em relação àqueles suplementados com 200mg do probiótico $/ \mathrm{kg}$ de ração, indicando que o probiótico tenha acionado seus mecanismos de ação, para restabelecer o desequilíbrio microbiano intestinal acarretado pela desmama.

$\mathrm{O}$ consumo diário de ração não foi afetado $(\mathrm{P}>0,05)$ pela suplementação de diferentes concentrações do probiótico, em nenhum dos períodos estudados. Entretanto, o ganho diário de peso e a conversão alimentar foram influenciados $(\mathrm{P}<0,05)$ pela suplementação de diferentes concentrações do probiótico (Tabela 5).

No Período 1, os animais que consumiram rações sem suplementação 
Rev. Bras. Saúde Prod. Anim., Salvador, v.14, n.1, p.248-258 jan./mar., 2013 http://www.rbspa.ufba.br ISSN 15199940

do probiótico apresentaram melhores $(\mathrm{P}<0,05)$ ganho diário de peso $\mathrm{e}$ conversão alimentar em relação àqueles suplementados com 300 $\mathrm{mg}$ do probiótico $/ \mathrm{kg}$ de ração, enquanto os leitões que consumiram rações suplementadas com 200mg do probiótico $/ \mathrm{kg}$ de ração, mostraram similares $(\mathrm{P}>0,05)$ ganho diário de peso e conversão alimentar aos dos demais tratamentos.

Tabela 5. Ganho diário de peso (GDP), consumo diário de ração (CDR) e conversão alimentar (CA) dos leitões em função da concentração de probiótico $(\mathrm{mg} / \mathrm{kg})$ e períodos

\begin{tabular}{|c|c|c|c|c|c|}
\hline Item & 0 & 200 & 300 & $\mathrm{CV}(\%)$ & $\mathrm{P}$ \\
\hline \multicolumn{6}{|c|}{ Período 1: 0 a 10 dias pós desmame } \\
\hline CDR (g) & $189 \pm 16$ & $157 \pm 11$ & $171 \pm 17$ & 26,30 & 0,43 \\
\hline GDP $(g)$ & $81 \pm 13^{\mathrm{a}}$ & $57 \pm 12^{\mathrm{ab}}$ & $44 \pm 9^{\mathrm{b}}$ & 60,89 & 0,04 \\
\hline $\mathrm{CA}(\mathrm{g} / \mathrm{g})$ & $2,97 \pm 0,56^{\mathrm{a}}$ & $3,29 \pm 0,32^{\mathrm{ab}}$ & $4,20 \pm 0,65^{\mathrm{b}}$ & 47,68 & 0,01 \\
\hline \multicolumn{6}{|c|}{ Período 2: 11 a 20 dias pós desmame } \\
\hline CDR (g) & $360 \pm 12$ & $366 \pm 12$ & $381 \pm 15$ & 8,26 & 0,58 \\
\hline GDP (g) & $261 \pm 18^{b}$ & $337 \pm 16^{\mathrm{a}}$ & $299 \pm 25^{\mathrm{ab}}$ & 15,40 & 0,03 \\
\hline $\mathrm{CA}(\mathrm{g} / \mathrm{g})$ & $1,39 \pm 0,07^{\mathrm{b}}$ & $1,09 \pm 0,05^{\mathrm{a}}$ & $1,30 \pm 0,09^{\mathrm{ab}}$ & 13,14 & 0,02 \\
\hline \multicolumn{6}{|c|}{ Período Total: 0 a 20 dias pós desmame } \\
\hline CDR (g) & $290 \pm 11$ & $277 \pm 3$ & $286 \pm 17$ & 8,86 & 0,79 \\
\hline GDP (g) & $191 \pm 8^{\mathrm{ab}}$ & $211 \pm 9^{\mathrm{a}}$ & $185 \pm 15^{\mathrm{b}}$ & 11,62 & 0,02 \\
\hline $\mathrm{CA}(\mathrm{g} / \mathrm{g})$ & $1,53 \pm 0,09^{\mathrm{ab}}$ & $1,33 \pm 0,04^{\mathrm{a}}$ & $1,57 \pm 0,05^{\mathrm{b}}$ & 10,83 & 0,04 \\
\hline
\end{tabular}

${ }^{\mathrm{a}, \mathrm{b}}$ Médias com letras iguais na linha não diferem entre si pelo teste de Tukey $(\mathrm{P}>0,05)$.

No Período 2, os leitões suplementados com $200 \mathrm{mg}$ do probiótico/kg de ração apresentaram melhores $(\mathrm{P}<0,05)$ ganho diário de peso e conversão alimentar em relação aos alimentados sem suplementação do probiótico. No entanto, o ganho diário de peso e a conversão alimentar dos leitões suplementados com $300 \mathrm{mg}$ de probiótico/kg de ração, foram semelhantes $(\mathrm{P}>0,05)$ aos demais.

No Período Total, os leitões suplementados com 200mg de probiótico $/ \mathrm{kg}$ de ração apresentaram melhores $(\mathrm{P}<0,05)$ ganho diário de peso e conversão alimentar em relação àqueles suplementados com $300 \mathrm{mg}$ de probiótico/kg de ração, enquanto, os animais sem suplementação do produto, apresentaram ganho diário de peso $\mathrm{e}$ conversão alimentar semelhantes $(\mathrm{P}>0,05)$ aos demais, estando de acordo com Budiño et al. (2006), Huaynate et al. (2006) e Utiyama et al. (2006).

Os coeficientes de variação no Período 1 foram elevados, diminuindo no Período 2 e estabilizando-se a valores normais no Período Total. Essas mudanças, possivelmente sejam devidas às condições fisiológicas, comportamentais e ao grau de adaptação inerentes dos leitões desmamados, principalmente nos primeiros dias pós desmame, caracterizado por falta de consumo de alimento, perda de peso e ocorrência de desarranjos intestinais.

Neste trabalho foi observado que a eficácia do probiótico depende também da dosagem utilizada. Assim, Roth \& Kirchgessner (1988) observaram que o ganho de peso total e a conversão alimentar de leitões melhoraram quando o probiótico foi fornecido nas concentrações de $5 \times 10^{8}$ ou $1 \times 10^{9}$ UFC 
de Bacillus spp. por kg de ração, mas não em concentrações menores. Eidelsburger et al. (1992) utilizaram o mesmo probiótico na concentração de $2,5 \times 10^{8}$ UFC por kg de ração e o ganho de peso e o consumo de ração caíram 8,1 e $9,0 \%$, respectivamente, enquanto a conversão alimentar melhorou 5,6\%. Da mesma forma, Kyriakis et al. (1999) observaram que Bacillus Licheniformis foi mais efetivo no controle da $E$. coli enterotoxigênica em leitões na concentração de $1 \times 10^{7}$ UFC por $\mathrm{kg}$ de ração que uma concentração dez vezes menor. Essas observações são discordantes com os resultados deste estudo, visto que o desempenho dos leitões foi melhor quando se adicionou a menor concentração de probiótico às rações, provavelmente pela falta de proporção adequada entre os microrganismos que compõem o produto. Neste estudo, foram observadas melhorias de $10 \%$ e $15 \%$ no ganho diário de peso e na conversão alimentar, respectivamente, nos leitões suplementados com probiótico, em relação ao grupo sem suplementação. Estes resultados foram superiores aos encontrados por Stewart \& Chesson (1993), de 4,8\% para ganho diário de peso e Close (2000), de $2,5 \%$ e $6,8 \%$ para ganho diário de peso e conversão alimentar, respectivamente. Essa variabilidade de resultados pode estar associada à diferença das espécies dos microrganismos do probiótico, concentração do probiótico, e pelas condições imunológicas do animal e sanitárias do ambiente de criação.

Notou-se que nos primeiros dez dias, as inclusões de 200 e $300 \mathrm{mg}$ de probiótico/kg de ração, reduziu o desempenho, apresentando, no entanto, recuperação e melhora nos dez dias subseqüentes. Uma possível explicação para o ocorrido é que pode ter havido adaptação da microbiota intestinal do hospedeiro aos microrganismos do probiótico. Outra hipótese refere-se aos efeitos dos microrganismos do probiótico sobre o sistema imunológico do hospedeiro nos primeiros dias, que podem acarretar baixo desempenho (SILVA \& NÖRNBERG, 2003). Semelhantes resultados foram observados por Utiyama et al. (2006).

O desempenho e a incidência de diarréia em leitões recém desmamados não foram alterados pela suplementação de diferentes concentrações do probiótico, quando comparados aos animais que não receberam o probiótico. No entanto, leitões suplementados com 200mg do probiótico/kg de ração mostraram melhor desempenho que leitões suplementados com $300 \mathrm{mg}$ do probiótico $/ \mathrm{kg}$ de ração. As características do sistema digestório não foram alteradas pelas diferentes concentrações do probiótico utilizado, as quais foram afetadas apenas pela idade dos animais.

\section{REFERÊNCIAS}

ALEXOPOULOS, C.; GEORGOULAKIS, I.E.; TZIVARA, A.; KRITAS, S.K.; SIOCHU, A.; KYRIAKIS, S.C. Field evaluation of the efficacy of a probiotic containing Bacillus licheniformis and Bacillus subtilis spores, on the health status and performance of sows and their litters. Journal of Animal Physiology and Animal Nutrition, v. 88, p.381-392, 2004.
BARROS, D.S.; CARAMORI
JÚNIOR, J.G.; CORRÊA, V.S.;
ABREU, J.G.; FRAGA, A.L.;
MAINARDI, F.; DUTRA, V. Efeito da adição de probiótico e prebiótico sobre o ganho de peso, consumo de ração e ocorrência de diarréia em leitões na fase 
de aleitamento. Revista Brasileira de Saúde e Produção Animal [online], v.9, n.3, p.469-479, 2008.

BHANDARI, S.K.; XU, B.; NYACHOTI, C.M.; GIESTING, D.W.; KRAUSE, D.O. Evaluation of alternatives to antibiotics using an Escherichia coli $\mathrm{K} 88+$ model of piglet diarrhea: Effects on gut microbial ecology. Journal of Animal Science, v.86, p. 836-847, 2008.

BRIDI, A.M.; OLIVEIRA, A; FONSECA, N.A.N.; SHIMOKOMAKI, M.; COUTINHO, L.L.; SILVA, C.A. Efeito do genótipo halotano, da ractopamina e do sexo do animal na qualidade da carne suína. Revista Brasileira de Zootecnia, v.35, p.20272033, 2006.

BUDIÑO, F.E.L.; THOMAZ, M.C.; KRONKA, R.N.; NAKAGUI, L.S.O.; TUCCI, F.M.; FRAGA, A.L.; SCANDOLERA, J.A.; ROBLESHUAYNATE, R.A. Effect of probiotic and prebiotic inclusion in weaned piglets diets on structure and ultrastructure of small intestine. Brazilian Archives of Biology and Technology, v.48, n.6, p.921-929, 2005.

BUDIÑO, F.E.L.; THOMAZ, M.C.; KRONKA, R.N.; TUCCI, F.M.; FRAGA, A.L.; SCANDOLERA, J.A.; ROBLES-HUAYNATE, R.A.; NADAI, A.; CORREIA, R.C. Efeito da adição de probiótico e/ou prebiótico em dietas de leitões desmamados sobre o desempenho, incidência de diarréia e contagem de coliformes totais. Brazilian Journal of Veterinary Research and Animal Science, v.43, p.59-67, 2006.

CLOSE, W.H. Producing pigs without antibiotic growth promoters. Advances in Pork Production, v.11, p.47-56, 2000.
CORREA, V.S.; CARAMORI JÚNIOR, J.G.; VIEITES, F.M.; ABREU, J.G.; BARROS, D.S. Probiótico líquido para leitões lactentes em diferentes idades. Revista Brasileira de Saúde e Produção Animal [online], v.11, n.3, p.827-837, 2010.

EIDELSBURGER, U.;

KIRCHGESSNER, M.; ROTH, F.X. Influence of fumaric acid, hydrochloric acid, sodium formate, tylosin and toyocerin on daily weight gain, feed intake, feed conversion rate and digestibility. II. Investigations about the nutritive efficacy of organic acids in the rearing of piglets. Journal of Animal Physiology and Animal Nutrition, v.68, n. $4 / 5$, p.82-92, 1992.

GUARNER, F.; MALAGELADA, J.R. Gut flora in health and disease. The Lancet, v.360, p.512-518, 2003.

KYRIAKIS, S.C.; TSILOYIANNIS, V.K.; VLEMMAS, J.; SARRIS, K.; TSINAS, A.C.; ALEXOPOULOS, C.; JANSEGERS, L. The effect of probiotic LSP 122 on the control of post-weaning diarrhoea syndrome of piglets. Research in Veterinary Science, v.67, n.3, p.223$228,1999$.

HUAYNATE, R.A.R.; THOMAZ, M.C.; KRONKA, R.N.; FRAGA, A.L.; SCANDOLERA, A.J.; BUDIÑO, F.E.L. Uso de probiótico em dietas de suínos: Incidência de diarréia, desempenho zootécnico e digestibilidade de rações.

Brazilian Journal of Veterinary Research and Animal Science, v.43, n.5, p.664-673, 2006.

ROSTAGNO, H.S.; TEIXEIRA, L.F.A.; DONZELE, J.L.; GOMES, P.C.; OLIVEIRA, P.F.; LOPES, C.D.; FERREIRA, A.S.; TOLEDO, S.L.B. 
Rev. Bras. Saúde Prod. Anim., Salvador, v.14, n.1, p.248-258 jan./mar., 2013 http://www.rbspa.ufba.br ISSN 15199940

Tabelas brasileiras para aves e suínos composição de alimentos e exigências nutricionais de aves e suínos. Viçosa, MG: Universidade Federal de Viçosa, 2005, 186p.

ROTH, F.X.; KIRCHGESSNER, M. Nutritive effects of toyocerin 1. Piglet Feeding, v.41, p.58-62, 1988.

SCANDOLERA, A.J.; THOMAZ, M.C.; KRONKA, R.N.; FRAGA, A.L.; BUDIÑO, F.E.L.; ROBLES-

HUAYNATE, R.A.; RUIZ, U.S.;

CRISTANI, J. Efeito de fontes protéicas na dieta sobre a morfologia intestinal e o desenvolvimento pancreático de leitões recém-desmamados. Revista Brasileira de Zootecnia, v.34, n.6, p.2355-2368, 2005.

SHU, Q.; QU, F.; GILL, H.S. Probiotic treatment using Bifidobacterium lactis HN019 reduces weanling diarrhea associated with rotavirus and Escherichia coli infection in a piglet model. Journal of Pediatric Gastroenterology and Nutrition, v.33, p.171- 177, 2001.

SILVA, C.A.; BRIDI, A.M.; CASTROGOMEZ, R.J.H.; SILVA, C.R.B.; MENEGUCCI, C.G.; CARVALHO, B.B. Uso de probiótico e antibióticos na alimentação de leitões em fase de creche. Semina: Ciências Agrárias, v.28, n.4, p.739-746, 2007.

SILVA, L.P.; NÖRNBERG, J.L. Prebióticos na nutrição de nãoruminantes. Ciência Rural, v.33, n.4, p.55-65, 2003.

SAS Institute. Statistical analysis system: user's guide. Version 9.1. Cary, USA, 2003.
STEWART, C.S.; CHESSON, A.

Making sense of probiotics. Pig

Veterinary Journal, v.31, p.11-33, 1993.

THOMAZ, M.C.; HANNAS, M.I.;

KRONKA, R.N.; TUCCI, F.M.;

SCANDOLERA, A.J.; BUDIÑO, F.E.L.

Influence of swine plasma and whole egg in rations of weaned piglets on structure and ultra-structure of intestinal mucous development. ARS Veterinária, v.27, p.246-254, 2011.

TUCCI, F.M.; THOMAZ, M.C.; NAKAGHI, L.S.O.; HANNAS, M.I.; SCANDOLERA, A.J.; BUDIÑO, F.E.L. Efeito da adição de agentes tróficos na dieta de leitões desmamados sobre a estrutura e ultra-estrutura do intestino delgado e sobre o desempenho. Arquivo Brasileiro de Medicina Veterinária e Zootecnia, v.63, p.931-940, 2011.

UTIYAMA, C.E.; OETTING, L.L.; GIANI, P.A.; RUIZ, U.S.; MIYADA, V.S. Efeitos de antimicrobianos, prebióticos, probióticos e extratos vegetais sobre a microbiota intestinal, a freqüência de diarréia e o desempenho de leitões recém-desmamados. Revista Brasileira de Zootecnia, v.35, n.6, p.2359-2367, 2006.

VENTE-SPREEUWENBERG, M.A.M.; VERDONK, J.M.A.J.; BAKKER, G.C.M.; BEYNEN, A.C.; VERSTEGEN, M.W.A. Effect of dietary protein source on feed intake and small intestinal morphology in newly weaned piglets. Livestock Production Science, v.86, n.1, p.169-177, 2004.

Data de recebimento: 11/12/2012

Data de aprovação: 26/03/2013 